\title{
To Re-Archive an Archive. An Experience in Art Therapy over 25 Years and 25,000 Images ${ }^{\dagger}$
}

\author{
Malvina Borgherini ${ }^{1, *}$ and Gregorio Merlin ${ }^{2}$ \\ 1 MeLa Media Lab, Department of Architecture and Arts, University Iuav of Venice, 30125 Venice, Italy \\ 2 Parco dei Tigli Care Home, Art Therapy Atelier, 35037 Padua, Italy; gregoriomerlin@gmail.com \\ * Correspondence: borgheri@iuav.it; Tel.: +39-333-278-0690 \\ + Presented at the International and Interdisciplinary Conference IMMAGINI? Image and Imagination \\ between Representation, Communication, Education and Psychology, Brixen, Italy, 27-28 November 2017.
}

Published: 25 December 2017

\begin{abstract}
From the early 1990s Parco dei Tigli, a psychiatric care home, has been running an art therapy atelier where hundreds of residents have been able to express themselves through drawing and dialogue, both with themselves and with others, occasionally for the very first time and using the image as a tool. Looking at the idea of an archive's profanation rather than its institutionalization, the project we are proposing here is to re-classify a collection of over 25,000 images; to create a new collection which, in its rejection of a unique order and through a continual reorganization, will thus regain its reason for being.
\end{abstract}

Keywords: pre-verbal imagery; art therapy; digital archive; data visualization

1.

When on 7 December 1966, in a broadcast on France Culture radio, Michel Foucault expounded upon heterotopias, his comment on the treatment and environs that societies have devised for the mentally ill over the centuries, these relayed reflections had already been consolidated into his first influential book Madness and Civilization: A History of Insanity in the Age of Reason [1]. Unlike utopias, "they do not belong to any space because they are born in the heads of people from the in-between of their words, from within the deep layers of their stories or even from the place-less site of their dreams". These counter-sites propounded by Foucault are real places but absolutely other from those we live in. Some heterotopias had been set up by societies over the years to welcome people into a community in times of biological crisis, such as youth academies or wards for expectant mothers, but already by the 1960s the heterotopias that Foucault defined as crises have almost all disappeared, replaced by sites set aside for deviations. Psychiatric hospitals and prisons are some of these locations "that society establishes in its margins, [...] reserved for individuals whose behavior is deviant in relation to the mean, or the required norm" by the rest of the community [2].

With the Italian Mental Health Act of 1978 (Legge 180) promoted by Franco Basaglia, inspirational for his contemporary views on mental health, a state-of-the-art health reform was launched who's major outcome would be the closure of old mental institutions and their deinstitutionalization into decentralized health services. The Marco Cavallo experiment, carried out in 1973 between January and March at the "P" workshop in Trieste's San Giovanni psychiatric hospital, involving a group of artists led by Giuliano Scabia [3], not only built bridges between the interned inmates and the city's inhabitants, but it bolstered the notion that artistic expression, the image, could give back a voice to those who had been deprived of expression for centuries. The "P" workshop became one of the key initiatives for superseding the asylum: the world goes in and the insane come out. 
2.

The modern concept of mental health, and more specifically, art therapy, took shape in an environment that evolved over time, the result of an intriguing chain of events. In the second half of the nineteenth century, with scientific resurgence motivated by positivism, the function of the asylum changed from place of segregation to place of care. Nascent neuropsychiatry paid attention to patient behavior and, in particular, to their free artistic depictions. Between 1864 and 1903, Paul-Max Simon, a physician at Blois Asylum in France, was so impressed with the drawings of his psychiatric patients that he started to take notes. Physicians at that time, examining potential nosographic aspects within an image, considered graphic production as one of the many symptoms to be analyzed, but whose particular focus was in the display of any divulged interiority that might be revealed in a unique and original way. Only Simon's notes remain, none of the patients' drawings [4].
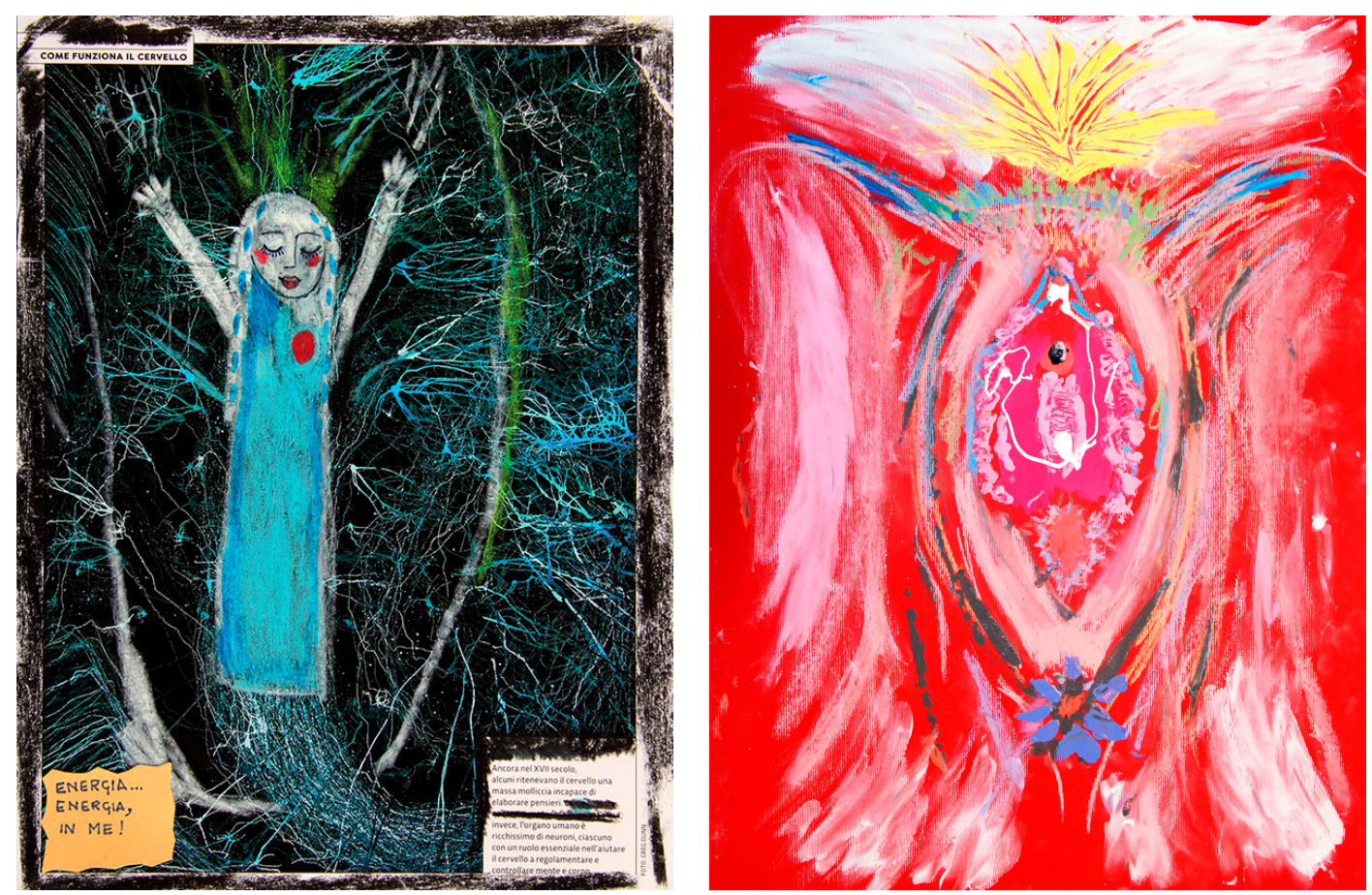

Figure 1. On (left) Viviana (aged 45, psychotic disorder), New Energy in Me; On (right) Lucia (aged 54, histrionic personality disorder), It Could Be a Representation.

Also in 1864, Cesare Lombroso-a doctor, lawyer and founder of a contentious field in anthropology that he designated "criminal anthropology" - published a book in Italy entitled Genio $e$ Follia in which he gives great weight to the content of patients' designs but, in this case too, he preferred to catalogue them as mere symptoms, emphasizing the characteristics of excess or bizarreness rather than exploring other possible interpretations [5]. On the other hand, Enrico Morselli's 1885 work Manuale di Semeitoica delle malattie mentali (A Guide to the Semiotics of Mental Illness) did accentuate the importance of the psychiatric patient's pictorial creativity, both as a document chronologically correlated to aspects of the illness as well as a potential for enriching the patient's awareness by way of demonstrating evident symptoms that are clinically undetectable [6].

In 1905 the so-called Musée de la Folie was opened. It was a repository of drawings and paintings by the mentally ill, attended to in the best way possible at that time by Auguste Marie, a student of Jean-Martin Charcot and head consultant at the Villejuif Asylum on the outskirts of Paris. This is one of the first collections in which there was a proper attempt at cataloging and archiving the material. In 1912 Henri Marcel Faÿ's Réflexions sur l'art et les aliénés, he highlights the similarities between the works of the Fauves, Expressionist and Cubist painters together with the works of the mentally estranged [7]. Then five years later, Hans Prinzhorn began collecting and archiving the pictures produced by psychopathy sufferers from the University of Heidelberg Psychiatric Clinic. In 1922 he published these studies in his influential work Bildnerei der Geisteskranken [8]. The actually 
book aroused more interest in the artistic sphere than the psychiatric one: Max Ernst introduced France to its influence, Paul Klee made use of it in his Bauhaus lectures, Jean Dubuffet, once having read it, decided to devote himself completely to art and coins the term Art Brut. Prinzhorn was the first psychiatrist who not only sought after the aesthetic-expressive content but also the personality of the creator, introducing the possibility of using pictorial creations not only diagnostically but also therapeutically. He clearly distinguishes the work of art from the depicted expression of patients, arguing that there is always, for any artist, the desire to communicate whilst for the psychiatric patient the artwork embodies the persistent endeavor to understand themselves and to concretizes some inner aspect that remains unknown and beyond their grasp. Prinzhorn actuated research that would meld together in psychoanalysis, with the aim of uncovering successively more in-depth understanding of a patient's inner psyche. By 1921 the Prinzhorn Collection consisted of around 5000 works by 450 patients. After Prinzhorn left the university, the hoard was stored away in an attic and forgotten, only coming to light in the 1960s. Since 2001 the collection has been open for viewing in a former lecture hall of Heidelberg University. Jean Vinchon's 1924 book L'art et la folie [9] presents an involuntary yet important contribution to The Surrealist Manifesto, in which Antonin Artaud openly criticizes psychiatry of the time, arguing that "crazy artists" should be left free to express themselves without restriction and without any "attempt to cure".

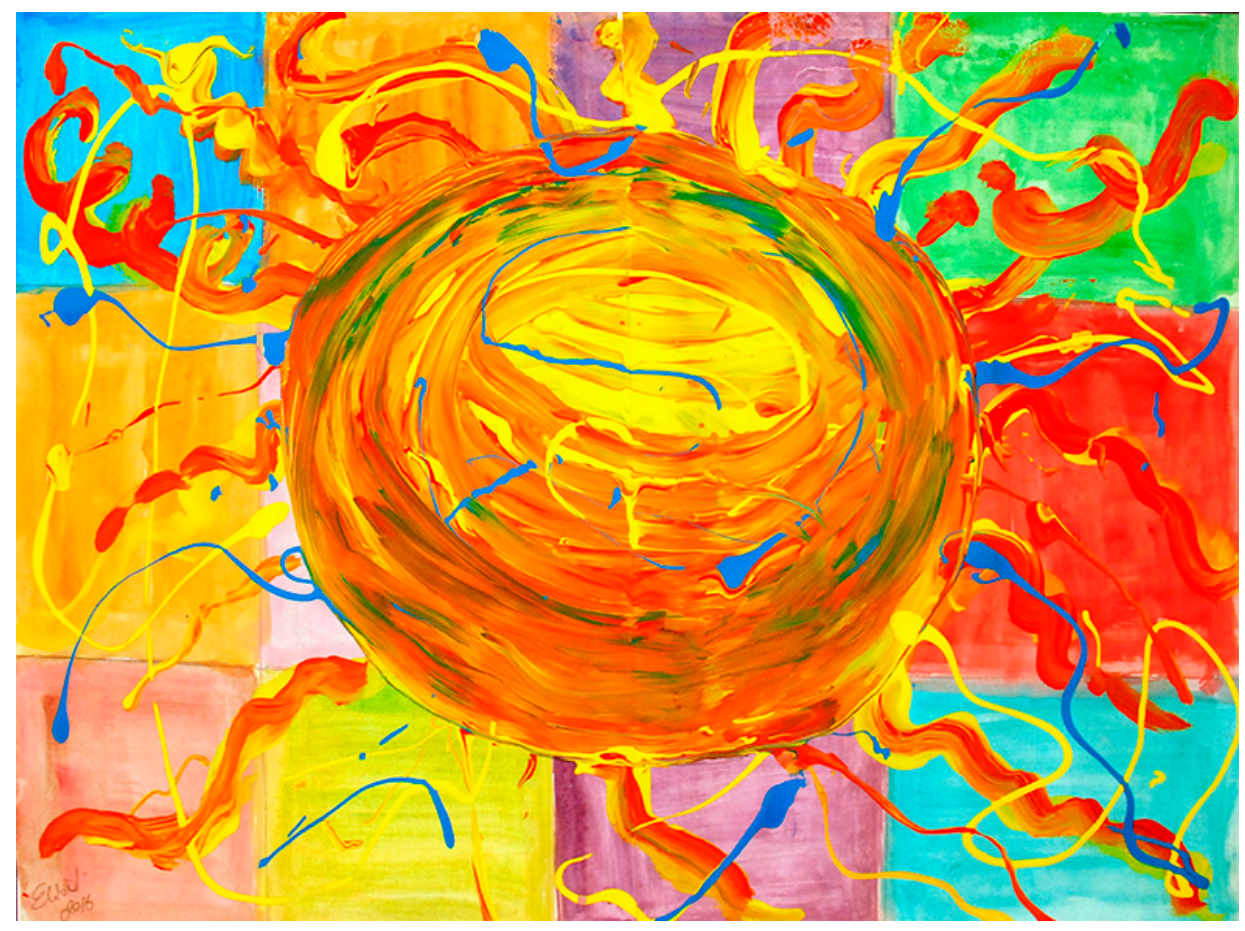

Figure 2. Susanna (aged 47, bipolar disorder), An Engaging Movement, Producing a Change.

At the beginning of the 1940s, Jean Dubuffet decided to dedicate himself entirely to the search for a new and different art, an art created and hailing from a "strange land", divorced from any previous form or artistic category, a "crude gold" which, according to him, had to be prospect for in the asylums, or lawless places, anywhere that art of the academy had never been encountered. $\mathrm{He}$ began to collect a large number of works and drawings by the mentally ill and convinced the Parisian Galerie René Drouin to host his Le Foyer de l'Art Brut exhibition (1947). Subsequently the Compagnie de l'Art Brut was formed, bringing together exponents such as André Breton, Michel Tapié and others. Over a period of about twenty years he managed to gather and catalogue 5000 works and, by the 1960s, he envisaged donating them to French institutions. But given the scarce enthusiasm shown by France for his collection, he resolved to transfer it to Lausanne, Switzerland, where the Musée de l'Art Brut was inaugurated in 1976. This collection, which today comprises over 70,000 works by more than a thousand originators, it remains the most significant international reference for artworks produced by psychiatric patients. 


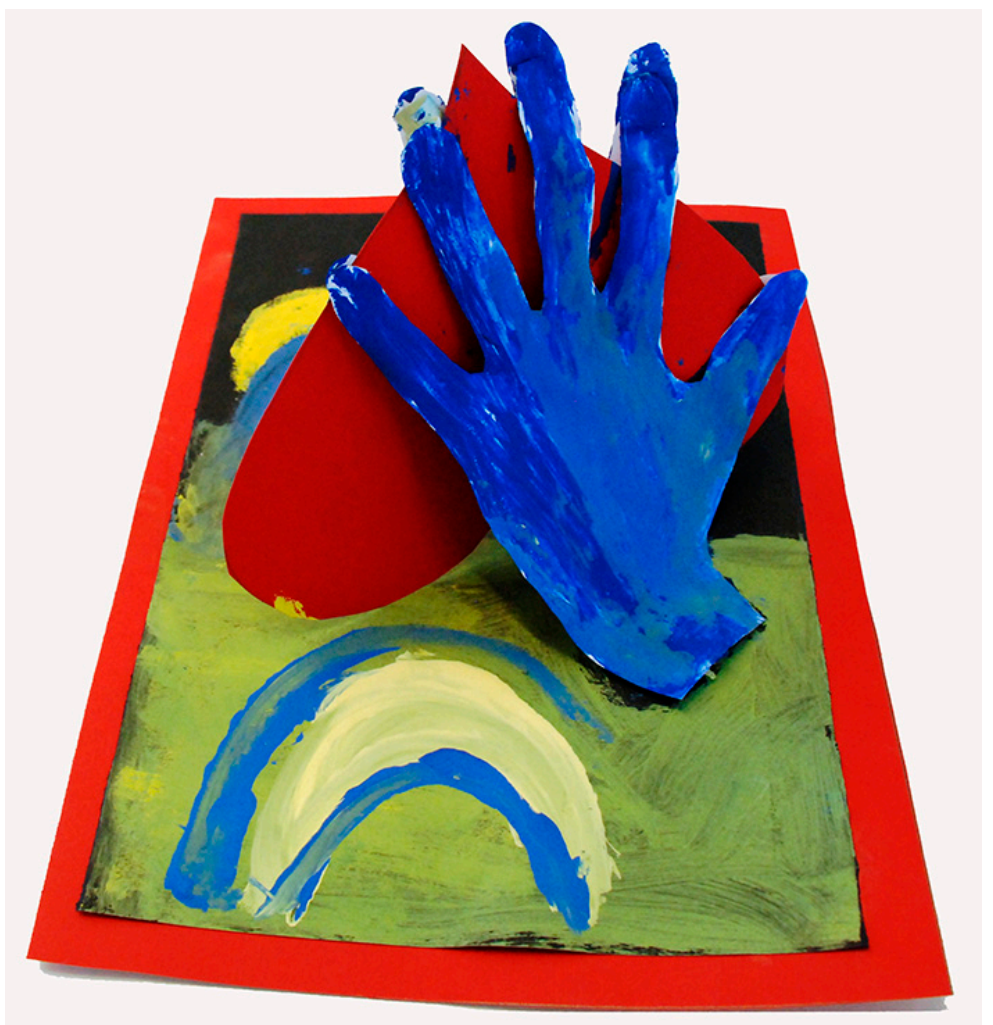

Figure 3. Maurizio (aged 36, alcohol abuse), I Hope She Welcomes Me Once More.

The foundations of art therapy begin to coalesce and consolidate thanks to the input of psychoanalysis. In the same year that the first Musée de la Folie was inaugurated, Sigmund Freud published Der Witz und seine Beziehung zum Unbewußten. Artworks are not discussed directly in the treatise, but he does argue for the possibility of expressing unconscious content through an art-form as long as it affords the mastery of "the primary process" [10]. According to Freud, the ego filters and masks unconscious fantasies, which then find expression in language or art through the preconscious mechanisms of displacement, condensation, and sublimation. In Totem und Tabu Freud argues that the function of art in developed societies, is to represent the omnipotence of the most quintessential thoughts of primitive peoples, children and, of course, psychopaths [11]. In his 1919 essay Das Unheimliche, Freud describes the essential function of art as a way of enjoying personal fantasies without experiencing guilt, in the form of libido sublimation [12]. Art, as with omnipotent reverie and dreams, allows for a withdrawal from reality, but while the dream is generated exclusively by the dreamer's unconscious, the work of art is a "dream in the presence of reason" and therefore assumes the value of social elaboration, recognizable and available for use by the beholder. In a work of art, therefore, the role of sublimation is fundamental: a process in which strong impulsive tensions are expressed by the artist with the intent of securing a shared gratification between artist and viewer.

Ernst Kris, once he became a psychoanalyst, after having been an ardent student of art history at Vienna University during the 1920s, would go on to make an important contribution to the cross-discipline of psychoanalysis and art. Freud entrusted him with the direction of Imago, a periodical dating back to 1912. It amounted to a creative think-tank for the theory of the subconscious, dealing with literature, language and art. Kris is the only Freudian author not to have studied the creative process exclusively from the perspective of subconscious motivation: he asserts that in creative undertakings the ego manifests a specific capacity to regulate regression in a controlled manner without being overwhelmed. Furthermore, he proposed that the concept of "regression in the service of the ego", a regression of the primary process from which "inspiration" prevails, is characterized by the availability of archaic and undifferentiated patterns of thought, thus without departing from the ego functions that retain "the secondary process" attributes, while 
recovering and emphasizing subconscious content, rendering it visible and worth telling. There is, according to Kris, a reorganization of these functions in the task of concentrating and channeling an expressive force. This phase of "elaboration" completes the inspiration stage by keeping the ego on a plane of reality yet allowing artistic production to emerge. The lack of processing and the impossibility of controlled regression in the psychiatric patient almost always result in indecipherable pictorial production. The work contains no conscious planning, and therefore remains quite unreliable and unhelpful to both the author and observer [13].

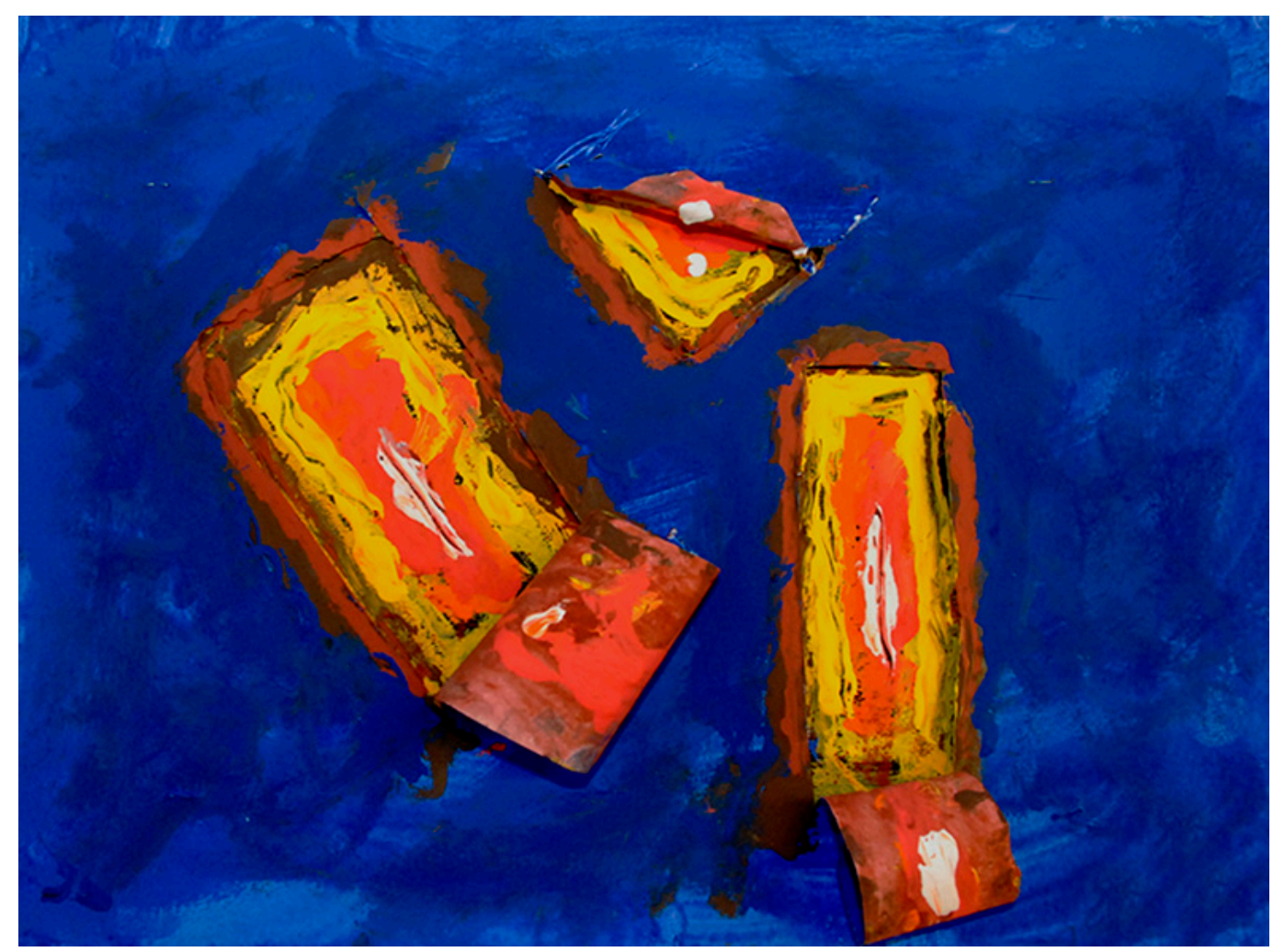

Figure 4. Tommaso (aged 28, depressive borderline personality disorder), Wounds that Open and Close Like Sardine Cans.

Melanie Klein analyses the creative act in the light of her concept of "reparation". The basis for creating, according to her research, lies in the possibility of overcoming the depressive state. Recognizing an object or other person in their entirety, both good and bad, triggers conflict in the subject and forces one to admit the coexistence of both good and evil within oneself. The guilt allied to the depressive state originates from this process. The creative act, in any expressive form, amounts to a repair and restoration of the other, resulting in a reparation of the ego. In his foundational book Playing and Reality (Tavistock, London 1971), Donald Winnicott submits that there can be no complete destruction of any human being's creativity [14]. Moreover, he suggests that even in the most serious psycho-pathologies there always has been, albeit hidden, a creative and original secret life. Since the patient himself doesn't know and doesn't believe that he possesses this creativity, it is up to the therapist to contrive a way that will allow them to recognize this innate ability to express oneself creatively. If Freud, Kris and Klein describe the meaning of the artwork specifically in terms of communication, Winnicott recognizes that art therapy allows a patient to be put in touch with their own creativity. Gaetano Benedetti provides a rather convincing proof of the importance of artistic activity for the schizophrenic patient in his 1980 book Alienazione e personazione nella psicoterapia della malattia mentale (Alienation and personage within psychotherapy for mental illness) [15]. In a series of patient drawings and paintings, he not only demonstrates the main difficulties in psychotherapy but also the different phases of the therapeutic process. Quotations from famous artists, such as René Magritte, also encourages a comparison between artistic (in the true sense of the term) and psychopathological production, easily distinguishable from the 
"suffering contamination" of the schizophrenic who produces an image without a clear idea or desire to communicate with the external world. However, it remains indisputable that the psychotic patient is more likely to communicate through images than through words. The book's colored plates show the occurrence of verbal psychotherapy. The paintings are described with great vivacity and the various stages are demarcated, almost always preceded by tangible developments and presenting the "good original", the patient's personal experience, expressed through graphic signs and symbols. Benedetti's experience confirms that in treating serious psychological disorders when verbal ability is limited or absent, graphic expression can become the primary way in which a patient can form a therapeutic alliance with the therapist. The profound notion that "many more images can be produced than thoughts thought" is Benedetti's.

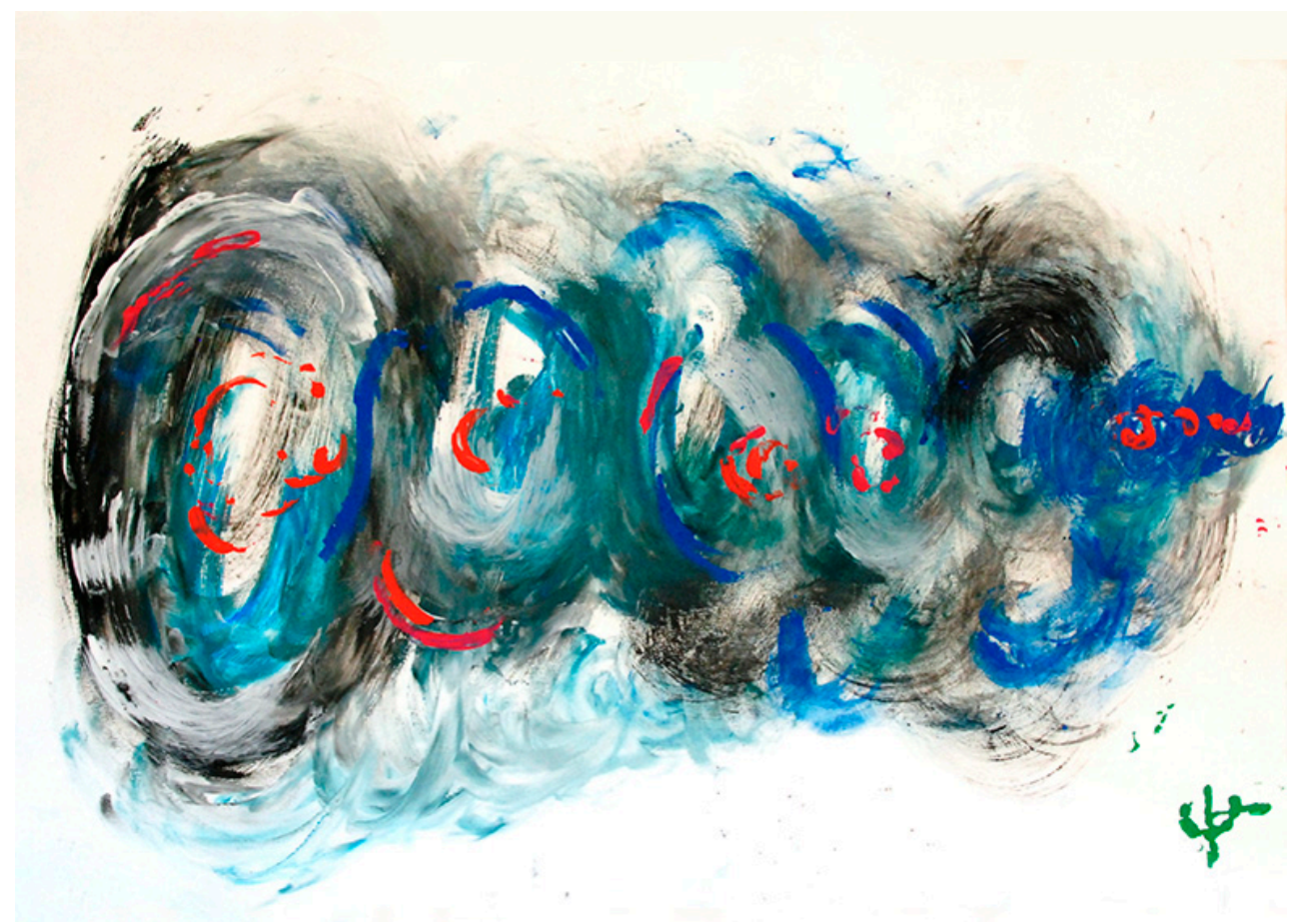

Figure 5. Kevin (aged 23, multi-substance abuse), Vortices, Vortices that Pull You in.

The framework of shared rules in art therapy application can be attributed to Margaret Naumburg. Considered the pre-eminent theoretician behind this therapeutic approach, she had previously founded the Walden School in New York City in 1914 where she spent years exploring teaching methods with the children, later branching into art therapy after the second world war. Naumburg termed her work Dynamically Oriented Art Therapy, borrowing from psychoanalytic concepts and principles, arguing that pictorial creation is, in all respects, a form of nonverbal communication that can be analyzed in just the same way as dreams and fantasies. Free associations are generated by the content of the drawing and can be discussed and shared with the art therapist in a way that is similar to that of the psychoanalyst who analyses a recounted dream. To support this thesis, in her 1958 paper Art Therapy: Its Scope and Function, Naumburg cites Freud's passage about a patient who could not recount a dream verbally, yet told him that it would be easier to draw it [16]. From this and many other considerations, Naumburg argues that a picture is closer to the subconscious, predominantly a visual issue, because it does not require any "verbal translation". In pictorial expression, censorship is significantly lessened and many symbolic devices are made available to convey different meanings. Naumburg firmly emphasizes the ongoing relationship between patient and therapist: before the 1930s the therapist studied the finished image without any comparison with their creator, thus without drawing interpretations and conclusions based upon the attested psychopathology and on the basis of multiple cataloguing that considered the image just one of the many symptoms. In Naumburg's view, the work of the patient ought to be carried out in 
the presence of the therapist, who is thus able to derive important insights from something like the way the materials are handled and, more generally, from the behavior of the patient while they realize their creation. The art therapist's work consists in gradually encouraging the patient to discover by themselves the meaning underlying their own artwork. This is stimulated by fostering free association, thereby easing the passage between image and word.

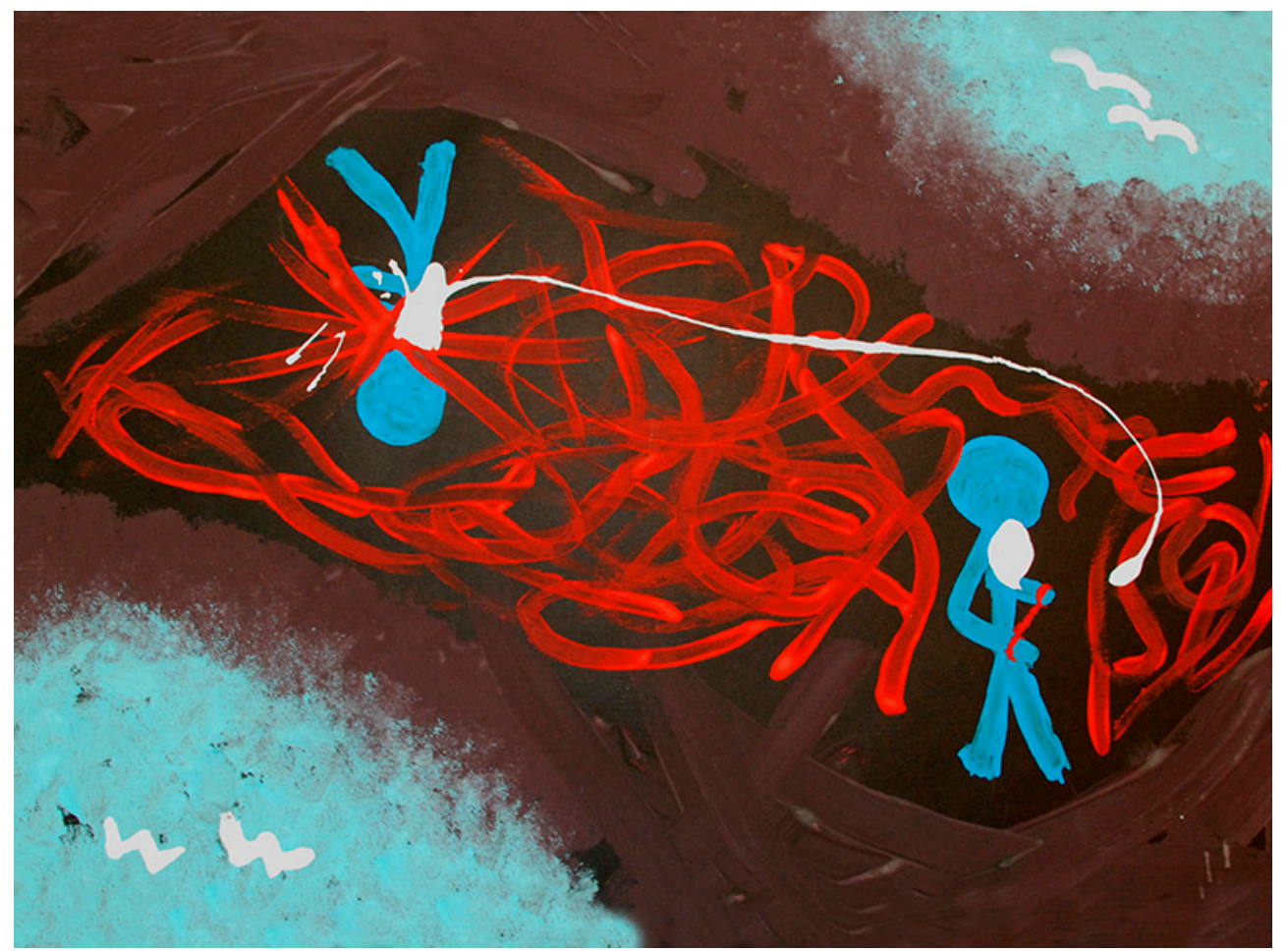

Figure 6. Marta (aged 38, psychotic disorder), The Child Who Did Not Want to Come and the One Who Will Not Come Anymore.

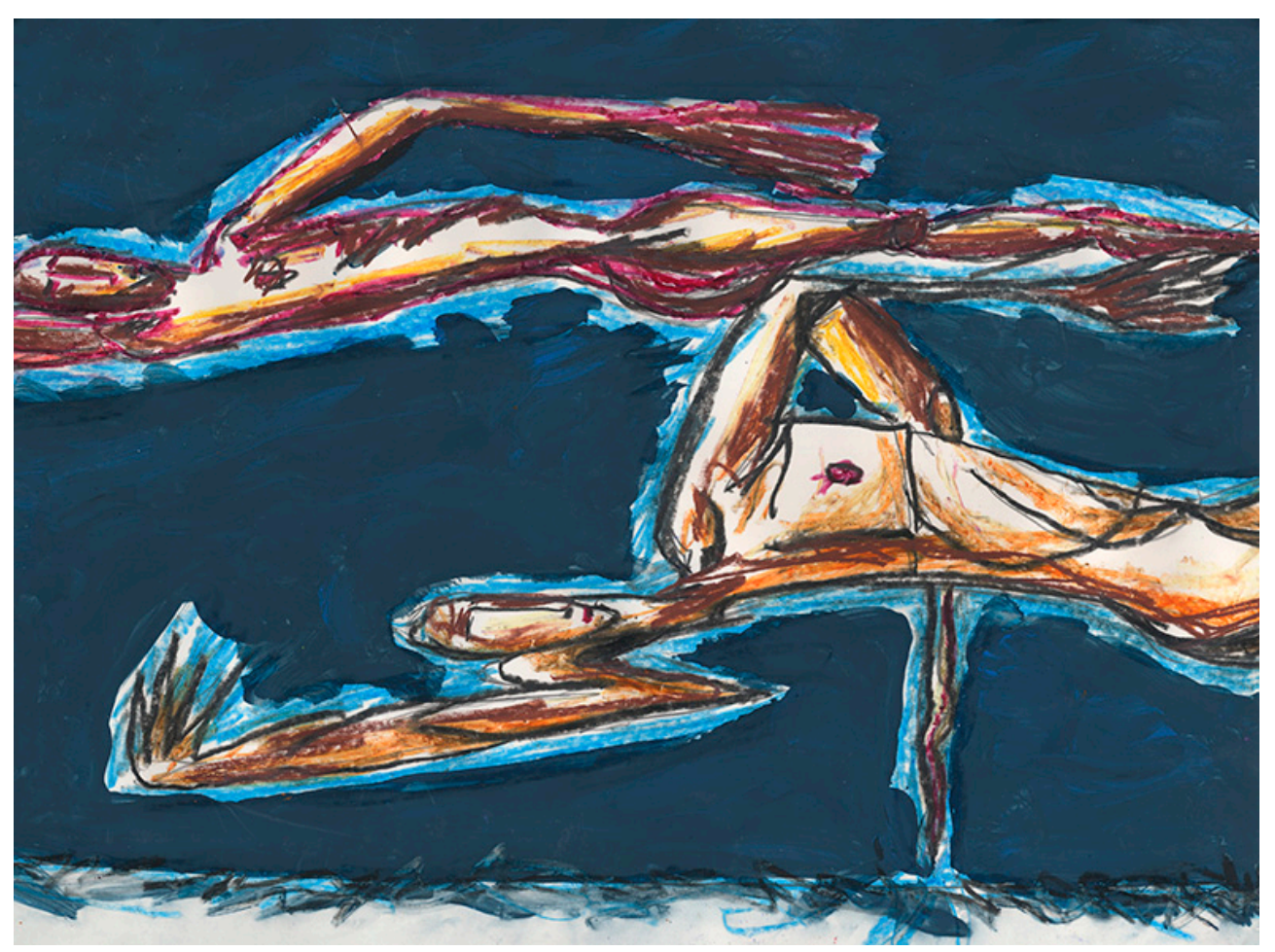

Figure 7. Ferdinando (aged 32, narcissistic personality disorder and opiate abuse), The Elegance of Movement. 
3.

Since the early 1990s, Parco dei Tigli, a psychiatric care home, has had an ongoing active art therapy workshop. Hundreds of residents have been able to express themselves pictorially and thereby open-up a dialogue with themselves and others, often for the first time, through the device of image-making. One of the theoretical bases through which the group operate is Kris's concept of "regression in the service of the ego", which is closely linked to Winnicott's thoughts on creativity and its persistence, even in cases of serious psychopathology. The use of artistic creation privileges communication, making it possible to access the primary process without being overwhelmed. There is a simultaneous appeal to functions of the ego like attention, criticism and sensory-motor coordination which can coexist with the freest expression of the subconscious. It also seeks to inspire a psychological reorganization by strengthening those aspects of the ego that are able to communicate to the image's creator, and to the other, more primitive modes of thought and content that are not otherwise expressed. The main purpose is to promote subconscious pictorial expression, especially in those patients with whom it is difficult to maintain a direct and anchored verbal communication. By making use of the "analogue level" of the image-in other words, an examination of reality through the image which can reveal contradictions and paradoxes-it becomes easier to express moods, emotions and very intense feelings. Engaging in group activities further encourages interpersonal communication between participants and the therapist. Often the individual artworks are enriched by the impressions expressed by the other participants, allowing for the coexistence of different readings and making a further stage of exchange and comparison possible. The importance of projecting inner feelings towards the outside, onto the blank paper, is particularly stressed. Such gestures can result in an appreciation of extraversion that itself feels liberating. Moreover, the production of the image, compared to verbal communication, is perceived as less demanding, therefore not as threatening. If an anxious or depressed patient receives a candid comment on their designed image, they may always rebuff any such conjecture, stating that their intent was altogether something different. There are four therapy groups of patients at present at the care home, each of whom undergoes a weekly selection, based on their pathology: depressive disorders, dual diagnosis (e.g., psychopathology plus addiction), personality disorders, anxiety and other conditions. The patient is summoned to the group by a psychiatrist, the ward supervisor. These are open groups, with an average attendance of six sessions. The activity consists of a first half in which the art materials are used freely, and a second in which everyone who wants to is given the opportunity to talk about the images produced. In the initial presentation, which is very straightforward, two concepts are expressed: the activity is not for the production of skilled artwork so much as for the unimpeded use of materials, and the activity is not a test but an opportunity to simply express oneself. For the first-time participants it might feel daunting to be faced with a blank sheet without any suggestions about what to do, but this initial quandary is soon understood for its deeper meaning: the design process must be completely spontaneous, not influenced by suggestions or, much less, copied. It's originality must be pure. Harking back to Naumburg's insight, one can appreciate the value of observing a patient while they make use of the materials. Even prior to the end result, one can note a wide range of contingencies that are instructive, even at a diagnostic level. The depressed patient, for example, tends to be slow and very rarely makes use of colors. The obsessive patient is so enthused about tinkering with the meticulous details that they are loathed to conclude their elaborations; in the paranoid's design, an eye always appears as a symbol of exasperating external control; the bipolar patient, in the manic phase, goes beyond using the sheets and colors, while the narcissistic or histrionic personality evaluates the materials provided as utterly inadequate for purpose and tends to impose immoderate demands. Another element of great interest is the significant difference that patients have in relation to their creativity. Some elderly ladies, who have spent their lives responding to the demands of their domestic situation, almost completely losing their own identity, lament their (supposed) inability to render even the most simple design; whilst the younger patients often overplay the part of the exuberant artist, using up a great deal of materials in the process. In all cases, however, it is possible to identify the primary trait, not just the pathological hallmark but also the implied characteristic of personality. There have been 
striking cases where the picture produced in the workshop anticipated the contents of the following session of psychotherapy, or else communicated long forgotten experiences or signaled behavior that prevented the development of an adequate therapeutic alliance with the care team. It is often recommended that the patient privately discusses their artwork with the psychotherapist precisely because the graphic content appears so much more striking than the verbal one. Over the sequence of picture production, the changes in the patient during the therapy are always taken into account; the way the experiences are processed, the effects of psychiatric drugs, any progress made in communication skills. Each individual patient leaves a personal story made up of images. These are all kept, principally as a form of respect, for it does not seem right to throw away such a specific testimony of a particular moment in a person's life. A patient on occasion, during a second admission or after discharge, has asked to have another look at their own designs: by accompanying them in this memory venture, one can witness the reminiscent power of the image and its effect, whether of endearment or of estrangement.

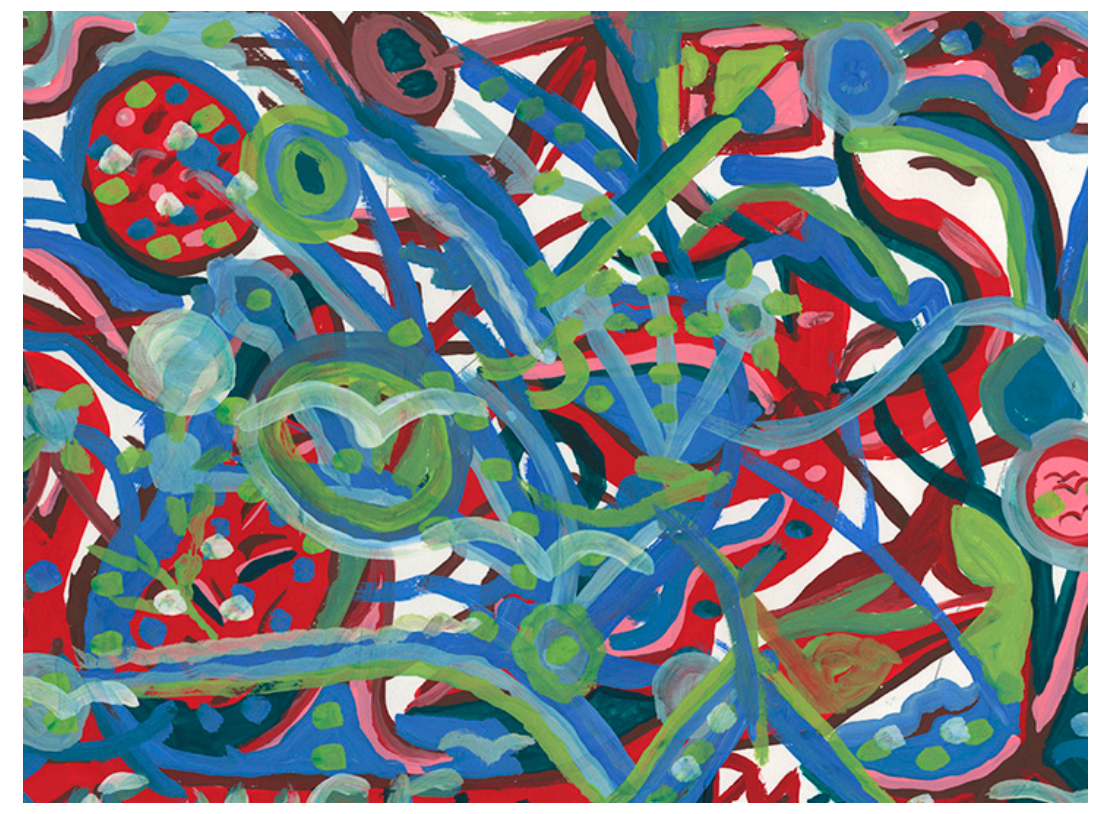

Figure 8. Marcella (aged 41, borderline personality disorder), Agitation.

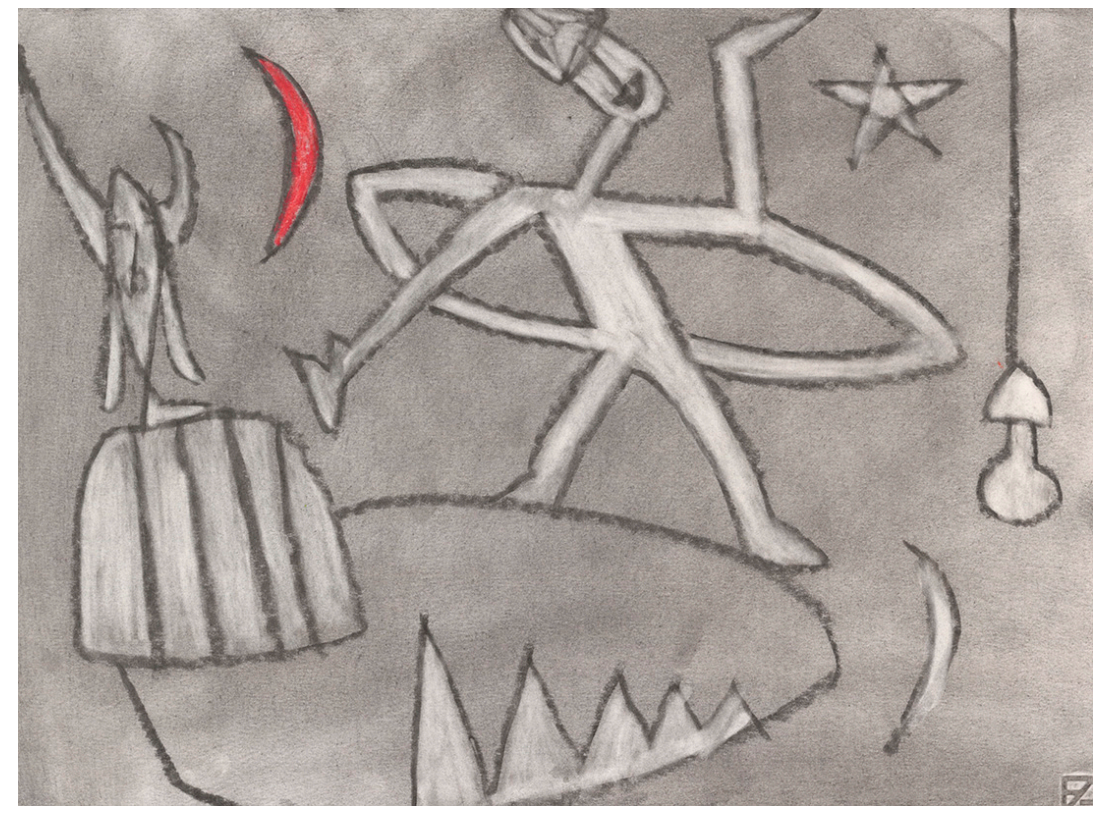

Figure 9. Gianpaolo (aged 29, depressive disorder and drug abuse) Discussions, Conversations, Reasoning, at the End Everything Returns to the Same Point. 
4.

The verb "re-archive" was not chosen casually for the presentation of this project. It is linked to an extraordinarily long-standing art therapy endeavor run by a single steadfast psychotherapist and within one abiding healthcare facility. It was a matter of personal professional choice as to how to scrupulously document these images (and occasionally models) of this unique group therapy-followed by the consequent accumulation of artifacts, coupled with a rudimentary cataloguing such that each "work" corresponded to the creator's name and production date-and it was backed from the outset by the Parco dei Tigli care home which helped allocate and organize the space required by a studio-workshop, one that not only hosted the working groups but could also collate the results and associated "written" dialogues. Thanks to a recent deliberation, the re-archiving of this collection will be carried out as part of a university design course. Not merely a case-study for an international and interdisciplinary conference, this project could conceivably open up new avenues for study, such a patrimony could ferment much analysis and cross-disciplinary exchange.

In order to allow as many people as possible to view a collection of about 25,000 images-to date the entirety of the archive-it was first thought best to proceed with the scanning of a photographic reproduction of each single work. But on contemplating the idea further, that plan seemed more like a desecration of the archive (a forgetting by heart, to quote Vincenzo Agnetti) rather than its institutionalization. In other words, it is also a little like looking at that in-between territory-of other spaces, a heterotopy to evoke Foucault-that is not so much (or only) the "virtual" space of the network platform through which the archive is accessed, as the actual space where "viewers" and authors can meet, which weave-in the warp and weft of an ever-expanding collection. Thus an archive that, in its rejection of categorical order and in its continuous reorganization, reclaims its raison d'être. An archive whose visual corpus not only ends up being a diagnostic tool but also a family album of sorts that records the first tentative murmurings of a persona, who within a new circle, tries to establish some form of contact with the world. A family album that, through sharing openly and through ensuing modifications, notes and comments of a subsequent broader community, becomes enhanced by an aggregation of entries and quotes that tallies with the corresponding images. By way of vivid traces these images record tangible clues about fears, feelings of inadequacy, the sufferings of isolated members of a community. At the same time, however, they display an incredible force bursting out, the intensity of finally being able to express oneself while simultaneously share their angst, observing it for the first time from the outside, exposing it to another's gaze. Every story has its own trajectory, embedded in the circumstances which shaped them over the years. Everyone is a star in its own right, yet all these scintillating specks take on the semblance of clustered constellations that can orientate travelers if beheld in unison. Such traces as these could allow one to read the collection from any number of angles; historical, social, anthropological, not only medical and scientific. The distress of an individual, as well as the community to which one belongs, is nothing but a reflection of a political and economic situation that has conditioned the way in which these Italian citizens have lived since the Second World War, encompassing the radical transformation of daily life over the last thirty years.

Let us imagine a reading of these symptoms as running through multiple stratification, that suggest subsequent layers of sedimentation over time, a stratigraphy for the situating of thought. Think also of diagrammatic plans that simulate team movements. Hence a reading that is not only about the creative expressions of various patients, or just patients in dialogue between themselves or with fellow creators, or just with the therapist. Another plane of interaction is possible for the viewers and/or artists in the moment in which they create or peruse through the cartography that maps them to their emergent group. In short, mappings that facilitate the escape of an insider as well as the entry of an outsider.

One could engage in exercises of reading/re-writing (as some have proposed) that could start from a single element, then to the overall body of the collection, altering space-time relationships, taking in approaches that branch off and lead to unforeseen destinations via unexpected directions: (1) to look at a single mark, to read it as if it is a world in itself, yet also see it as an element of a set of marks that makes up the design; (2) read a sequence of drawings-produced by the same patient, 
within a limited time span which corresponds to the period of residency in the care facility-rewritten as if they were frames of a sped-up film; (3) map-out a sort of diagram in which pictures by several patients, all produced over the same period, are organized into groups that highlight various forms of distress according to; gender, age, the diversity in geographical, social and cultural backgrounds; (4) map-making, locating the isles that cluster into archipelagoes, the collection seemingly forms a continent if viewed long distance, a landform spanning twenty-five years; (5) compile an atlas of images that by analogy or contrast exhibit significant historical-political events of the last decades-marshaled from old or new media; newspapers to television, smartphones to tattoos-woven in to the collection's individual narratives. This multi-linearity, which refutes both a stringent order for the archive and an elementary amassing of a database, allows the placing of diverse fragments in relation to each other and thus creates an interaction that can in no way be prearranged. The problem of rescuing the reader from the univocality of narratives thus finds a possible solution: not in suggesting new answers, but rather through the process of reformulating the questions themselves.

Author Contributions: Sections 1 and 4 were written by Malvina Borgherini, Sections 2 to 3 by Gregorio Merlin. In accordance with legislation governing the use of personal data, image creators will be identified by way of fictitious names only.

Conflicts of Interest: The authors declare no conflict of interest.

\section{References}

1. Foucault, M. Madness and Civilization: A History of Insanity in the Age of Reason; Plon: Paris, France, 1964.

2. Foucault, M. Of Other Spaces: Utopias and Heterotopias, translated by Jay Miskowiec. Archit. Mouv. Contin. 1984, 5, 46-49.

3. Scabia, G. Marco Cavallo. Da un Ospedale Psichiatrico la Vera Storia che ha Cambiato il Modo di Essere del Teatro e Della Cura; Alphabeta: Merano, Italy, 2011; ISBN 9788872231562.

4. Paul-Max, S. Les Maladies de l'Esprit; J.B. Bailliers: Paris, France, 1891.

5. Lombroso, C. The Man of Genius; Walter Scott: London, UK, 1891.

6. Morselli, E. Manuale di Semeiotica Delle Malattie Mentali; Vallardi: Milano, Italy, 1885.

7. Fay, H.-M. Réflexions sur l'art et les Aliénés. Æsculape Magazine, November 1912.

8. Prinzhorn, H. Artistry of the Mentally Ill: A Contribution to the Psychology and Psychopathology of Configuration; Springer: New York, NY, USA, 1972.

9. Vinchon, J. L'art e la Folie; Librairie Stock: Paris, France, 1924.

10. Freud, S. Jokes and Their Relation to the Unconscious. In The Standard Edition of the Complete Psychological Works of Sigmund Freud; Strachey, J., Freud, A., Eds.; Hogarth Press: London, UK, 1960; Volume VIII.

11. Freud, S. Totem and Taboo: Resemblances between the Mental Lives of Savages and Neurotics; Translated by Brill, A.A.; Moffat Yard \& Company: New York, NY, USA, 1918.

12. Freud, S. The Uncanny. In The Standard Edition cit; Strachey, F., Ed.; Hogarth Press: London, UK 1955; Volume XVII, pp. 218-252 (or Das Unheimliche ed.; Imago 1919, 5, 5-6, 297-324).

13. Kris, E. Psychoanalytic Explorations in Art; International Universities Press: New York, NY, USA, 1952.

14. Winnicott, D. Playing and Reality; Tavistock: London, UK, 1971.

15. Benedetti, G. Alienazione e Personazione Nella Psicoterapia Della Malattia Mentale; Einaudi: Torino, Italy, 1980.

16. Naumburg, M. Art-Therapy: Its Scope and Function. In Clinical Applications of Projective Drawings; Hammer, E.F., Ed.; Thomas: Springfield, IL, USA, 1958; pp. 509-599.

(C) 2017 by the authors. Licensee MDPI, Basel, Switzerland. This article is an open access article distributed under the terms and conditions of the Creative Commons Attribution (CC BY) license (http://creativecommons.org/licenses/by/4.0/). 